\title{
Foraging strategy predicts species-specific patterns of pollen foraging by honey bees and bumble bees
}

\author{
Danny Minahan ${ }^{1}$ and Johanne Brunet ${ }^{2}$ \\ ${ }^{1}$ Hebrew University of Jerusalem Robert H Smith Faculty of Agriculture Food and \\ Environment \\ ${ }^{2}$ USDA-ARS Vegetable Crops Research Unit
}

May 6, 2020

\begin{abstract}
Honey bees and bumble bees are generalist eusocial bees that collect resources from a variety of plant taxa. Both bee species have distinct foraging strategies that affect patterns of resource collection, with implications for designing pollinator friendly habitat management schemes. Using a comparative approach, we examined the pollen foraging patterns of the honey bee (Apis mellifera) and common eastern bumble bee (Bombus impatiens) in a suburban-agricultural landscape. We tested predictions stemming from the bees' known foraging strategies of dance communication or trapline foraging, respectively, and collected pollen from returning foragers of each bee species over five time periods at each of three sites. We quantified the frequency of flower constant foragers, the richness and diversity of pollen collected by a colony, and whether honey bees or bumble bees show preferences by comparing the taxonomic identity of pollen collected to resources available. Analyses were done at the pollen morphotype and plant family levels. Within a foraging trip, honey bees foraged on a single plant family more frequently than bumble bees throughout the summer, except during July, when both species demonstrated a similar frequency of flower constancy. Pollen diversity was greater for bumble bees relative to honey bees, and both bee species collected less diverse pollen in June. Finally, bumble bees preferred the Fabaceae_Tricolporate pollen morphotype (Trifolium repens or Medicago sativa), but avoided Apiaceae, while honey bees foraged randomly showing no evidence of preference. These results support the hypothesis that species level foraging strategies affect how bees exploit pollen resources. Explicitly considering pollinator foraging strategy when designing agri-environment schemes will inform the most appropriate arrangement of floral resources within developed landscapes, thereby promoting both pollinator health and pollination services of bee-dependent crops.
\end{abstract}

\section{Introduction}

Bees are important pollinators of a variety of crops and wildflowers, with their ecosystem services being valued at \euro153 billion (Gallai, Salles, Settele, \& Vaissière, 2009). Honey bees have been introduced for crop pollination around the globe, and when present, contribute to approximately $19 \%$ of all crop plant visits in a region (Hung, Kingston, Albrecht, Holway, \& Kohn, 2018). Wild bees are also known to contribute to increases in fruit production for pollinator-dependent crops (Garibaldi et al., 2013), and similar environmental factors contribute to both honey bee and wild bee health and conservation (Evans, Smart, Cariveau, \& Spivak, 2018). The taxonomic identity and relative abundance of floral resources collected by bee species can vary through time (Baum, Rubink, Coulson, \& Bryant, 2004; Wood, Kaplan, \& Szendrei, 2018). In addition, foraging strategies that facilitate the collection of resources, such as nectar and pollen, are variable among bee species (Rollin et al., 2013; Saleh \& Chittka, 2007; Visscher \& Seeley, 1982). To facilitate pollinator conservation, it is imperative to understand how foraging strategy influences patterns of resource collection.

Polylectic bees with an extended foraging season, such as honey bees and bumble bees, must navigate variable spatial and temporal resource availability challenges (Goulson, 1999). Pollen provides the primary 
source of macronutrients such as protein, lipids, sterols, and minerals, which are important for the growth and development of bee larvae and colonies (Avni, Hendriksma, Dag, Uni, \& Shafir, 2014; Di Pasquale et al., 2013; Moerman, Vanderplanck, Fournier, Jacquemart, \& Michez, 2017; Roulston \& Cane, 2002). However, not all plant pollen is equivalent in the relative amount of nutrients or their ratios (Roulston, Cane, \& Buchmann, 2000; Ruedenauer, Spaethe, Kooi, \& Leonhardt, 2019). Generalist bees, therefore, have to collect pollen from a variety of plant taxa to maintain a nutritional balance that ensures appropriate growth and development (Filipiak et al., 2017), and to mitigate other stressors such as infection from parasites (Di Pasquale et al. 2013). Collecting pollen from a variety of plant taxa can be a challenge in high intensity agricultural landscapes, and low diversity in collected pollen can reduce colony growth rate (Hass et al., 2019). The foraging strategy of bees, such as the presence of dance communication for honey bees and the trapline foraging of bumble bees, may help bees navigate such challenges and ensure the collection of an adequate diversity of pollen resources in their diet.

Both honey bees and bumble bees are generalist central place foragers that must locate, collect, and return to the nest with a diverse array of resources to provision the colony. A major foraging strategy employed by honey bees is dance communication, whereby scouts and successful foragers transmit information regarding the distance and direction to profitable resource patches (Seeley, Camazine, \& Sneyd, 1991; Visscher \& Seeley, 1982; Von Frisch, 1967). This strategy facilitates large scale recruitment to profitable resources, such as blooms of monoculture crops (Rollin et al., 2013). In contrast, bumble bee individuals develop and follow trapline foraging routes among known resource patches, 'majoring,' while simultaneously monitoring for changes in resource availability through 'minor' routes (Bernd, 1979; Ohashi \& Thomson 2009; Pasquaretta, Jeanson, Andalo, Chittka, \& Lihoreau, 2017; Woodgate, Makinson, Lim, Reynolds, \& Chittka, 2017). Trapline foraging by bumble bees is considered an optimal foraging strategy whereby individual bees learn, over successive foraging bouts the location of profitable resource patches and develop efficient routes that minimize distances traveled (Lihoreau et al., 2012; Woodgate et al., 2017). Based on these distinct foraging strategies, we expect honey bees to forage at monofloral resource patches, while individual bumble bees will disperse more evenly among all available resources, as has previously been observed in other agricultural systems (Rollin et al., 2013). We thus predict that bumble bees will be less flower constant relative to honey bees on individual foraging trips, where flower constancy is defined as the proportion of foraging bees that collect a single pollen morphotype during individual foraging bouts.

The frequency of flower constancy by individual bees can affect the richness and diversity of pollen collected at the colony level, along with the distribution of foragers among available resource patches. As bumble bees individually learn the location of rewarding flowers, and we expect individuals to collect from a greater number of plant types in single foraging bouts, we predict a greater richness of pollen collected by bumble bee colonies compared to honey bees. Furthermore, there is evidence indicating that bumble bees show preference for pollen resources, and that these preferences are sustained within and among colonies in a shared landscape (Saifuddin \& Jha, 2014). Such preferences could lead to increased evenness among the collected resources, and hence to greater pollen diversity. In contrast, we expect most honey bee foragers to be recruited to resources based on their abundance in the landscape (Rollin et al., 2013; Visscher \& Seeley, 1982), as opposed to demonstrating preferences, where a plant type would be visited more often than predicted based on its abundance. If we assume unequal abundance of plant types in the environment, we expect a lower evenness among collected resources, and together with lower species richness, lower pollen diversity for pollen collected by honey bees compared to bumble bees.

In the current study, we examined the pollen foraging behavior of honey bees (Apis mellifera) and bumble bees (Bombus impatiens ) in a shared landscape. We collected pollen from returning foragers of each bee species over five time periods at each of three sites in a suburban-agricultural landscape. We quantified the frequency of flower constant foragers, and the richness and diversity of pollen collected by colonies. In addition, we examined bees' preferences by comparing pollen collected to resources available. We tested the following predictions derived from the known foraging strategies for these two bee species: i) bumble bees are less flower constant relative to honey bees during a foraging trip; ii) bumble bee colonies collect a greater richness of pollen types relative to honey bees, along with greater pollen diversity and iii) honey bees 
forage randomly while bumble bees exhibit preferences for some plant types. Results are discussed in terms of differences in bee foraging strategies and how understanding such differences may be used to improve pollinator habitat and facilitate increased productivity in pollinator-dependent crops.

\section{Materials and Methods}

\section{Study area and bee species}

This study was conducted between June and September 2016 in southern Wisconsin, in an area of experimental and traditional agriculture and suburban development. We selected three sites based on qualitatively distinct plant species diversity. At each of these sites we placed one honey bee, Apis mellifera, and one bumble bee, Bombus impatiens, hive. Individual honey bee and bumble bee hives within a site were separated by $60-100 \mathrm{~m}$ (site $2: 60 \mathrm{~m}$; at sites 1 and $3: 100 \mathrm{~m}$ ). The distance between hive pairs among sites ranged from 700-1500m (sites 1-2: 700m; sites 1-3: 1500m; and sites 2-3: 1400m). Honey bees were housed in a two-frame wooden observation hive consisting of approximately 2000 workers and an actively laying queen. The bottom frame of each honey bee hive consisted of open and closed brood cells covering approximately half the frame, while the top frame was at least half covered in honey stores. The remaining cells were a mixture of empty cells or bee bread. Each hive was placed in a $1.2 \mathrm{~m}^{3}$ wooden box with an exit tunnel providing access outside. Bumble bee colonies (Koppert Biological Systems, Howell, MI, USA) consisted of approximately 75 workers at the beginning of the experiment, and each hive was housed in a small wooden shelter located $0.5 \mathrm{~m}$ off the ground.

\section{Pollen collection from returning foragers}

Pollen pellets were collected from individual bees as they returned from a foraging bout at each of the three sites, and over five time periods (Table 1). Within each time period we aimed to collect pollen from 40 honey bee and 20 bumble bee individuals on each of three days at each site, moving among sites each day to randomize data collection. Individual bees were immobilized in a cooler with ice, both pollen pellets removed, and each pellet separately stored in $1.5 \mathrm{~mL}$ microcentrifuge tube labeled with bee species, site, period, bee number, and pellet (a) or (b). Upon return to the laboratory, the pollen pellets were placed in a $-20^{\circ} \mathrm{C}$ freezer until ready for drying and weighing. One pollen pellet per bee was dried at $45^{\circ} \mathrm{C}$ for 24 hours, then used to identify plant morphotypes present in pollen loads.

Plant identity in pollen pellets

To identify the plants bees collected pollen from, each individual pollen pellet was crushed with a small pestle in a $1.5 \mathrm{~mL}$ microcentrifuge tube, followed by the addition of a Safarin-O pollen staining solution. Ten $\mu \mathrm{L}$ of homogenate was then placed onto a microscope slide, topped with a coverslip and sealed along the edges using clear nail polish (Jones, 2012). Using light microscopy, we counted and identified 500 pollen grains in each sample at 400x magnification. We verified that this is an appropriate sample size by rarefaction using the 'rarecurve' function in the 'vegan' package (Oksanen et al., 2019) in R (R Core Team 2013) (Appendix: Fig. S1). We made a library of visually distinct pollen morphotypes, and each pollen grain was identified at the lowest possible plant taxonomic level using reference samples collected from the study site, and online atlases (flickr.com/photos/161453633@N02/collections; paldat.org; blogs.cornell.edu/pollengrains; globalpollenproject.org). Following identification, the proportional abundance of each visually distinct pollen morphotype within a pollen pellet was calculated at both the plant family and pollen morphotype levels. We included a pollen morphotype if it occurred in at least $3 \%$ of all pollen identified within a pellet ([?] 15 out of 500 pollen grains).

\section{Flower constancy}

An individual bee was categorized as flower constant if the pollen pellet brought back to the hive contained pollen grains from a single morphotype or family. We calculated the proportion of foragers that were flower constant each day for a bee species, time period, and site. Linear mixed models (proc mixed in SAS v. 9.4) were used to determine the impact of bee species, time period, site, and their two-way interactions on the 
proportion of foragers that were flower constant. Day was the replicate in the model and bee species, period, site, and the two-way interactions were fixed effects. The three-way interaction term, site* period*species, was included as a random effect in the model, and provided the error term against which each fixed effect was tested. For each statistically significant factor, multiple means comparisons were performed to determine differences among levels of each factor.

\section{Pollen richness, diversity, and composition}

Pollen richness and diversity were calculated separately for each bee species in a day at a given period and site. Pollen richness represents the number of plant families or morphotypes present in the daily collection of pollen by individual colonies. Pollen diversity included richness, but also accounted for the relative abundance of each pollen type. To estimate diversity, we calculated Simpson Diversity Index (1-D) which is constrained between 0 and 1, where 1 indicates greatest diversity. Diversity was calculated using the 'diversity' function in the 'vegan' package (Oksanen et al., 2019) in R (R. Core Team, 2013). We used the linear mixed model (proc mixed in SAS v. 9.4) described in the flower constancy section to determine the impact of bee species, time period, site, and their two-way interactions on pollen richness and pollen diversity.

\section{Resource availability}

To quantify the resources available to bees, we performed monthly field surveys at each site, except for the July survey at site 1 that was missed. We established five $100 \times 2$ meter transects along the edges of experimental crop plantings or in fallow fields within 500 meters of the hives at each site, for a total of 15 transects per survey period over the three sites. One exception to the $500 \mathrm{~m}$ distance was one transect at site three which, due to measurement error, was placed 600 meters from the hives. Each transect was subsampled using ten 1-meter diameter circular quadrats. In each quadrat, we counted the number of individuals of each plant species. To estimate floral abundance, we counted either the number of flowers in a quadrat for plant species with non-clustered flowers (e.g. Caryophyllaceae) or the number of racemes (e.g. Fabaceae) or heads (e.g. Asteraceae) for plant species with clustered flowers. Because the absence of a plant species in a quadrat resulted in many zero counts, we estimated plant richness and diversity at the transect rather than the quadrat level. Plant richness and diversity were calculated at the levels of plant species and family, along with morphotype to align with pollen identification. Diversity was calculated using the Simpson D Index as described above for bee-collected pollen. The same categories established for pollen morphotypes in pollen pellets were used for plant resource morphotypes based on their pollen morphology (Table 2). We determined the impact of site and survey period on plant richness and diversity using a linear mixed model (proc mixed, SAS v. 9.4) with site and survey period as fixed effects, and their interaction as a random effect. A transect was the replicate in the model, and the fixed effects were tested against the two-way interaction error term.

\section{Bee preference for floral resources}

To determine whether bees demonstrate preferences for floral resources or foraged randomly, we compared the abundance of plant morphotypes in bee-collected pollen to the availability of plant resources in the environment. If bees forage randomly, we expect the representation of plants in pollen pellets to reflect plant resource availability. These analyses were done at the level of morphotypes, and to be included in the analyses a morphotype had to be present in both the pollen pellets and plant resource surveys at any point during the summer, but not necessarily in all periods. We examined the preference of each bee species over the entirety of the flowering season. We used period as a replicate and combined pollen collection periods 2 and 3 for these analyses to have equivalent periods for plant resource and pollen pellet collections (Table 1). The proportion of a morphotype in pollen pellets and resource surveys was calculated for each bee species during each comparable period, across all sites (Table 1). The data represent the mean proportion of a pollen type over all pollen pellets or over all resource survey quadrats for that period and bee species. Preference tests were performed separately for each bee species. We used a multivariate analysis of variance (MANOVA in proc GLM, SAS v.9.4) to determine if there were any overall preferences, followed by individual ANOVAs to test preference for individual morphotypes. A greater proportion of a morphotype in the pollen pellets 
relative to the resource surveys suggested a preference for that plant morphotype, while a lesser proportion was indicative of avoidance. The lack of a difference suggested that bees foraged randomly (i.e. based on the availability of plant resources).

\section{Results}

\section{Pollen collection and plant identity}

Rates of pollen foraging were low on some days, and ultimately, we collected 486 pollen pellets from bumble bees over 34 days, and 1048 from honey bees over 33 days (Appendix Table S1). Because no honey bee pollen foragers were caught at site 1 during period 3, this site/period combination was excluded from pollen analyses for honey bees. Over the experiment, bees collected pollen from 20 distinct plant morphotypes and 16 plant families (Table 2). The morphotype classifications below family included genus (e.g. Hemerocallis ) and species (e.g. Lotus corniculatus ). When we could distinguish distinct pollen morphotypes within a plant family but these morphotypes could not be accurately associated with a genus or species, we subdivided the family using defining features (e.g. Fabaceae_Tricolporate).

Over the flowering season, $65 \%$ of pollen returned to honey bee colonies by foragers was from plants in the Fabaceae family, in contrast to bumble bees who brought back $38 \%$ of pollen from Fabaceae, and $34 \%$ from Brassicaceae (Fig. 1a). Furthermore, over both bee species, Fabaceae was the most abundant pollen collected during all periods except for period five, when Asteraceae became the most abundant (31.3\%) plant family along with Brassicaceae (26.2\%), the latter being predominantly collected by bumble bees (Fig. 1b).

\section{Flower constancy}

There was a statistically significant interaction between the effects of bee species and period on the percentage of flower constant foragers at both the morphotype and family levels (Table 3; Fig 2). During all periods, except period 3, a greater proportion of honey bee foragers collected pollen from one plant morphotype or family (e.g. higher flower constancy) relative to bumble bees (Fig. 2). In period 3, rates of flower constancy were similar between the two bee species (Fig. 2). Flower constancy did not vary among sites for either bee species (Table 3 ).

\section{Pollen richness and diversity}

At the morphotype level, neither pollen richness, nor diversity varied between the two bee species, among periods, or sites (Table 3). At the family level, we observed a statistically significant interaction between the effects of period and bee species on pollen richness, and a statistically significant impact of both period and bee species on pollen diversity (Table 3). There is greater statistical power at the family relative to morphotype levels, due to the fewer number of families and greater sample size associated with each family. Bumble bees collected pollen from more plant families relative to honey bees in period one, while the opposite pattern was observed in period three (Fig. 3a). There were no statistically significant differences between bee species in periods two, four, or five (Fig. 3a). Overall, bumble bees collected pollen from (mean \pm se) $4.26 \pm 0.27$ plant families, and $5.38 \pm 0.35$ plant morphotypes on a given day, while honey bees foraged for pollen on $3.39 \pm 0.27$ plant families, and $4.36 \pm 0.33$ plant morphotypes. Bumble bees collected more diverse pollen (mean \pm se) $(0.54 \pm 0.03)$ relative to honey bees $(0.33 \pm 0.04)$ (Table 3$)$. In addition, over both bee species, pollen diversity values were lower in period one compared to periods three, four, and five (Fig. $3 \mathrm{~b}$ ).

\section{Plant resource richness and diversity}

Plant richness did not differ among periods but differed significantly among sites at the family level, but not at the species or morphotype level (Table 4; Appendix Fig S2). There were more plant families at site one $($ mean $\pm \mathrm{se})(4.4 \pm 0.93)$ than site two $(2.6 \pm 0.4)(\mathrm{df}=5 ; \mathrm{t}=3.34 ; \mathrm{P}=0.021)$, while site three $(3.0 \pm$ $0.45)$ did not differ from either site one or two $(\mathrm{P}>0.05)$. Moreover, plant diversity did not vary among sites or periods at any of the three classification levels (Table 4).

\section{Bee preferences for floral resources}


There were six morphotypes identified in both the pollen pellet and resource survey data (Table 2). These included Apiaceae,Asteraceae_Lophate, Asteraceae_Spines, Fabaceae_Tricolporate,_Lotus corniculatus, and Trifolium pratense. In addition,Monarda fistulosa and Poaceae were present in both data sets, but only once and were therefore not included in the analyses. Analyzing preference over all morphotypes provided marginal significance for bumble bees, but was not statistically significant for honey bees (Table 5). Analyses of individual pollen morphotypes revealed that bumble bees preferred Fabaceae_Tricolporate, and avoided Apiaceae, while there were no preferences detected for honey bees (Table 5; Fig. 4).

\section{Discussion}

Bumble bees were generally less flower constant during pollen collection than honey bees, supporting our prediction that trapline foraging results in a greater proportion of bees visiting more than one plant taxon for pollen collection during single foraging bouts. Likewise, the observation that honey bees tended to forage on a single plant type during a foraging bout supports the hypothesis that dance communication generates cohorts of individuals that forage on a single profitable patch (Visscher \& Seeley, 1982). At the colony level, the diversity of pollen collected by bumble bees was greater than that of honey bees, however the richness of pollen collected was temporally variable for both bee species (Fig.3). Similar differences in flower constancy and diversity were also observed between honey bees and bumble bees in agricultural systems in Germany (Leonhardt \& Blüthgen, 2012). Interestingly, during period three, we observed an increase in the rate of flower constancy, which was associated with a decrease in the richness of pollen collected by bumble bee colonies, with the opposite pattern observed in honey bees, supporting a link between individual and colony level foraging patterns. These results support the idea that foraging strategies, such as trapline foraging and dance communication help predict differences in pollen foraging patterns by different bee species. Such knowledge not only highlights interspecific differences in foraging patterns, but also informs questions concerning the dynamic responses of each bee species to spatiotemporal ecological challenges present in human altered landscapes. This type of information can be used to facilitate the development of pollinator friendly habitats that also support pollination of bee-dependent crops.

During period three the number of foraging bumble bees declined, while honey bees were regularly foraging for pollen at sites two and three, but not at site one (Appendix Table S1). We might expect changes in resource availability, which are known to mediate distinct responses among bee species, to contribute to the observed temporal foraging dynamics of honey bees and bumble bees (Jha \& Vandermeer, 2009). However, at the spatial scale of $500 \mathrm{~m}$ around each hive site we did not detect any temporal differences in the richness or diversity of plant resources available to bees (Appendix Fig. S2). Interestingly, in period 3, both bee species gathered pollen from plant families found outside the survey areas, such as Brassicaceae by bumble bees or Geraniaceae by honey bees (Table 2; Appendix Fig. S3). It has been suggested that summer is a challenging time for bees, possibly as a result of competition for shared resources (Couvillon, Schürch, \& Ratnieks, 2014; Minahan \& Brunet, 2018). In July, Bumble bee individuals foraged more frequently from single pollen sources, while more honey bee individuals visited multiple resources, and both bee species exploited new plant families for pollen. For honey bees, it would be interesting to determine if fewer foragers followed the dance communication during this period, which if true would suggest more bees scouting for resources, or visiting previously learned locations (Biesmeijer \& Seeley, 2005). Future studies should further examine life history and ecological factors associated with the temporal dynamics of pollen and nectar foraging, and how these are linked to distinct foraging strategies. Understanding these factors will improve the ability of conservation planners to select resource types and plan their spatial and temporal distributions according to the dynamic needs of pollinator communities.

As predicted based on the trapline foraging strategy, bumble bees demonstrated a preference for Fabaceae_Tricolporate but an avoidance of Apiaceae pollen, while honey bees foraged randomly, based on the floral abundance of plant families in the area. The preference for certain plant types when foraging for pollen could depend on differences in the amount of pollen made available by plants, with bumble bees being able to detect such differences (Brunet, Thairu, Henss, Link, \& Kluever, 2015). Preference could also be influenced by the ability of a bee species to handle and exploit particular flower morphologies (Raine and Chittka, 
2007), or the nutritional complement of pollen relative to other available resources (Somme et al. 2015). The observation of preference by bumble bees but not honey bees suggests a potentially greater ability of bumble bees to respond to floral traits such as fatty acid content of pollen (Ruedenauer et al., 2020) relative to honey bees. This may be necessary when using trapline foraging as opposed to dance communication as a foraging strategy.

There exist some challenges to our approach of determining preference. A first challenge is selecting an appropriate spatial scale and survey method to estimate floral resource availability. Our surveys were limited to $500 \mathrm{~m}$, which is likely to encompass many foraging trips, but not all, as bees can forage beyond this range (Beil, Horn, \& Schwabe, 2008; Danner, Molitor, Schiele, Härtel, \& Steffan-Dewenter, 2016; Nagamitsu, Tsukuba, Ushirokita, \& Konno, 2012). A second challenge is that pollen types must be present in both pollen pellets and resource surveys for our analyses. However, it can also be informative when pollen is found in resources but not bee collected pollen, or vice versa. For example, the absence of Linaria vulgaris ,Oxalis, and Phlox pollen in pollen pellets suggests that bees are avoiding these available resources. Plants only present in the pollen pellets, such as Geraniaceae, most likely came from home gardens, which can provide valuable resources for bees (Goulson, Lye, \& Darvill, 2008). These results highlight the challenge associated with analyzing preferences in complex human altered landscapes. However, future experiments should explicitly consider the diversity of habitat types present when studying pollinator foraging patterns and their relationship with foraging strategies.

\section{Applications to agriculture and conservation}

A frequently collected pollen morphotype, Fabaceae_Tricoloporate pollen, likely came from a mix of white clover and alfalfa, as honey bee and bumble bee foragers carrying pollen pellets were often observed foraging for pollen on these plant species (personal observation). While there were fields of soybean (Glycine max ) at the agricultural research station, the pollen of which could not be reliably distinguished from alfalfa or white clover in this study, soybean flowers are cleistogamous, and may not actually open and be accessible to bees (Erickson, 1975). On the other hand, alfalfa and white clover contain nutritional rewards that are attractive to pollinators, and white clover is frequently documented as being an abundantly collected pollen type by honey bees (Keller, Fluri, \& Imdorf, 2005). In other agricultural systems, the prevalence of weedy plants, such as white clover in collected pollen has been documented for honey bees (Requier et al., 2018), along with bumble bees and other wild bees (reviewed in Bretagnolle and Gaba 2015). In this study, bees did forage on diverse weedy resources such as those from Fabaceae and Asteraceae on the experimental farm, in addition to probable garden resources such as Geraniaceae by honey bees. Furthermore, we did not observe more than a few pollen grains (contamination levels) coming from maize over the entirety of the study despite the presence of maize fields at the agricultural research station. Honey bees have previously been observed collecting maize when available, but it may actually decrease the longevity of individuals when consumed exclusively (Höcherl, Siede, Illies, Gätschenberger, \& Tautz, 2012). These results suggest that bees avoid corn pollen when more favorable resources are present and emphasizes the importance of providing diverse resources for bees that persists throughout the flowering season in human altered systems.

\section{Conclusions}

Our results highlight distinct pollen collection patterns between two bee species in a northern temperate agricultural landscape, and support the idea that foraging strategies can be used to predict how bees will use resources in the landscape. Specifically, the dance communication of honey bees was associated with a greater proportion of bees remaining flower constant on foraging bouts, a behavior which would benefit seed production of monoculture bee-pollinated crops. Furthermore, a lack of preference suggests that abundance may be a primary driver of forage selection in honey bees, another trait that favors monoculture bee-pollinated crops. This contrasts with bumble bees that demonstrated a preference for Fabaceae_Tricoloporate pollen, most likely alfalfa and white clover, but an avoidance of Apiaceae, both plant types being relatively abundant at the agricultural research station (Appendix Fig. S2). Both bee species are polylectic and need a diverse pollen diet to sustain their colonies, and both were able to collect a moderate diversity of resources throughout the summer. Our results highlight the importance of considering foraging strategies 
when developing conservation schemes that promote pollinator health, and facilitate pollinator-dependent crop production, along with other ecosystem services related to plant-insect biodiversity.

\section{Author contributions}

DM and JB designed the experiment and methodology. DM collected data. DM and JB worked on data analysis with the help of a statistician. DM led the writing of the manuscript and JB contributed critically to the drafts.

\section{Acknowledgments}

We would like to thank Alexandra Kois and Kyle Krellwitz for assistance in the field and in pollen identification, along with Austin Staudinger, Erica Smith, Gabby Stamas, Cecilia Grinis, Oscar Li, and Drake Propson for assistance with pollen identification. We would also like to thank Dr. Murray Clayton for valuable assistance with statistical analyses. This work was supported by funds from the Garden Club of America - Centennial Pollinator Fellowship (2016) to DM, and funds from USDA-ARS to JB. The authors have no conflicts of interest to declare.

\section{Data availability statement}

Data will be made available via the Dryad Digital Repository

\section{References}

Avni, D., Hendriksma, H. P., Dag, A., Uni, Z., \& Shafir, S. (2014). Nutritional aspects of honey bee-collected pollen and constraints on colony development in the eastern Mediterranean. Journal of Insect Physiology , 69 (C), 65-73. https://doi.org/10.1016/j.jinsphys.2014.07.001

Baum, K. A., Rubink, W. L., Coulson, R. N., \& Bryant, V. M. (2004). Pollen Selection by Feral Honey Bee (Hymenoptera: Apidae) Colonies in a Coastal Prairie Landscape. Environmental Entomology ,33 (3), 727-739. https://doi.org/10.1603/0046-225X-33.3.727

Beil, M., Horn, H., \& Schwabe, A. (2008). Analysis of pollen loads in a wild bee community (Hymenoptera : Apidae) - a method for elucidating habitat use and foraging distances. Apidologie , 39 , 456-467. https://doi.org/10.1051/apido

Bernd, H. (1979). " Majoring " and "Minoring" by Foraging Bumblebees, Bombus Vagans : An Experimental Analysis. Ecology , 60 (2), 245-255.

Biesmeijer, J. C., \& Seeley, T. D. (2005). The use of waggle dance information by honey bees throughout their foraging careers.Behavioral Ecology and Sociobiology , 59 (1), 133-142. https://doi.org/10.1007/s00265-0050019-6

Bretagnolle, V., \& Gaba, S. (2015). Weeds for bees? A review.Agronomy for Sustainable Development , 35 (3), 891-909. https://doi.org/10.1007/s13593-015-0302-5

Brunet, J., Thairu, M. W., Henss, J. M., Link, R. I., \& Kluever, J. A. (2015). The Effects of Flower, Floral Display, and Reward Sizes on Bumblebee Foraging Behavior When Pollen Is the Reward and Plants Are Dichogamous. International Journal of Plant Sciences ,176 (9), 811-819. https://doi.org/10.1086/683339

Couvillon, M. J., Schurch, R., \& Ratnieks, F. L. W. (2014). Waggle dance distances as integrative indicators of seasonal foraging challenges. PLoS ONE , 9 (4), 1-7. https://doi.org/10.1371/journal.pone.0093495

Danner, N., Molitor, A. M., Schiele, S., Hartel, S., \& Steffan-Dewenter, I. (2016). Season and landscape composition affect pollen foraging distances and habitat use of Honey bees.Ecological Applications , 26 (6), 1920-1929. https://doi.org/10.1890/15-1840.1

Di Pasquale, G., Salignon, M., Le Conte, Y., Belzunces, L. P., Decourtye, A., Kretzschmar, A., .. Alaux, C. (2013). Influence of Pollen Nutrition on Honey Bee Health: Do Pollen Quality and Diversity Matter? PLOS ONE , 8 (8), 1-13. https://doi.org/10.1371/journal.pone.0072016 
Erickson, E. H. (1975). Variability of floral characteristics influences honey bee visitation to soybean blossoms 1. Crop Science ,15 (6), 767-771.

Evans, E., Smart, M., Cariveau, D., \& Spivak, M. (2018). Wild, native bees and managed honey bees benefit from similar agricultural land uses.Agriculture, Ecosystems and Environment, 268 (January), 162170. https://doi.org/10.1016/j.agee.2018.09.014

Filipiak, M., Kuszewska, K., Asselman, M., Denisow, B., Stawiarz, E., Woyciechowski, M., \& Weiner, J. (2017). Ecological stoichiometry of the honeybee: Pollen diversity and adequate species composition are needed to mitigate limitations imposed on the growth and development of bees by pollen quality. PLoS ONE (Vol. 12). https://doi.org/10.1371/journal.pone.0183236

Gallai, N., Salles, J. M., Settele, J., \& Vaissiere, B. E. (2009). Economic valuation of the vulnerability of world agriculture confronted with pollinator decline. Ecological Economics , 68 (3), 810-821. https://doi.org/10.1016/j.ecolecon.2008.06.014

Garibaldi, L. A., Steffan-dewenter, I., Winfree, R., Aizen, M. A., Bommarco, R., Cunningham, S. A., ... Carvalheiro, L. G. (2013). Wild pollinators enhance fruit set of crops regardless of honey bee abundance. Science, 339 (May), 1608-1611. https://doi.org/10.1126/science.1230200

Goulson, D. (1999). Foraging strategies of insects for gathering nectar and pollen, and implications for plant ecology and evolution.Perspectives in Plant Ecology, Evolution and Systematics ,2 (2), 185-209. https://doi.org/10.1078/1433-8319-00070

Goulson, D., Lye, G. C., \& Darvill, B. (2008). Diet breadth, coexistence and rarity in bumblebees. Biodiversity and Conservation , 17 (13), 3269-3288. https://doi.org/10.1007/s10531-008-9428-y

Hass, A. L., Brachmann, L., Batary, P., Clough, Y., Behling, H., \& Tscharntke, T. (2019). Maize-dominated landscapes reduce bumblebee colony growth through pollen diversity loss. Journal of Applied Ecology , 56 (2), 294-304. https://doi.org/10.1111/1365-2664.13296

Hocherl, N., Siede, R., Illies, I., Gatschenberger, H., \& Tautz, J. (2012). Evaluation of the nutritive value of maize for honey bees.Journal of Insect Physiology , 58 (2), 278-285. https://doi.org/10.1016/j.jinsphys.2011.12.001

Hung, K. L. J., Kingston, J. M., Albrecht, M., Holway, D. A., \& Kohn, J. R. (2018). The worldwide importance of honey bees as pollinators in natural habitats. Proceedings of the Royal Society B: Biological Sciences , 285 (1870). https://doi.org/10.1098/rspb.2017.2140

Jha, S., \& Vandermeer, J. H. (2009). Contrasting bee foraging in response to resource scale and local habitat management. Oikos ,118 (8), 1174-1180. https://doi.org/10.1111/j.1600-0706.2009.17523.x

Jones, G. D. (2012). Pollen analyses for pollination research, Unacetolyced pollen. Journal of Pollination Ecology ,9 (13), 96-107.

Keller, I., Fluri, P., \& Imdorf, A. (2005). Pollen nutrition and colony development in honey bees: Part I. Bee World , 86 (1), 3-10. https://doi.org/10.1080/0005772X.2005.11099641

Leonhardt, S. D., \& Bluthgen, N. (2012). The same, but different: Pollen foraging in honeybee and bumblebee colonies. Apidologie ,43 (4), 449-464. https://doi.org/10.1007/s13592-011-0112-y

Lihoreau, M., Raine, N. E., Reynolds, A. M., Stelzer, R. J., Lim, K. S., Smith, A. D., .. Chittka, L. (2012). Radar Tracking and Motion-Sensitive Cameras on Flowers Reveal the Development of Pollinator Multi-Destination Routes over Large Spatial Scales. PLoS Biology ,10 (9), 19-21. https://doi.org/10.1371/journal.pbio.1001392

Minahan, D. F., \& Brunet, J. (2018). Strong interspecific differences in foraging activity observed between honey bees and bumble bees using miniaturized radio frequency identification (RFID). Frontiers in Ecology and Evolution , 6 (OCT), 1-10. https://doi.org/10.3389/fevo.2018.00156 
Moerman, R., Vanderplanck, M., Fournier, D., Jacquemart, A. L., \& Michez, D. (2017). Pollen nutrients better explain bumblebee colony development than pollen diversity. Insect Conservation and Diversity , 10 (2). https://doi.org/10.1111/icad.12213

Nagamitsu, T., Tsukuba, S. A., Ushirokita, F., \& Konno, Y. (2012). Foraging habitats and floral resource use by colonies of long- and short-tongued bumble bee species in an agricultural landscape with kabocha squash fields. Applied Entomology and Zoology , 47 , 181-190. https://doi.org/10.1007/s13355-012-0106-x

Oksanen, J., F. Guillaume Blanchet, R. K., Legendre, P., Minchin, P. R., O'Hara, R. B., Simpson, G. L., ... M. Henry H. Stevens, H. W. (2019). Package 'vegan.' R Package Version 3.4.0 .

Pasquaretta, C., Jeanson, R., Andalo, C., Chittka, L., \& Lihoreau, M. (2017). Analysing plant-pollinator interactions with spatial movement networks. Ecological Entomology , 42 , 4-17. https://doi.org/10.1111/een.12446

R. Core Team. (2013). R: A language and environment for statistical computing.

Raine, N. E., \& Chittka, L. (2007). Flower constancy and memory dynamics in bumblebees (Hymenoptera: Apidae: Bombus). Entomologia Generalis , 29 (1), 179-199. https://doi.org/0171-8177/07/0029-0179

Requier, F., Odoux, J., Tamic, T., Moreau, N., Decourtye, A., Bretagnolle, V., .. Bretagnolle, V. (2018). Honey bee diet in intensive farmland habitats reveals an unexpectedly high flower richness and a major role of weeds. Ecological Applications , 25 (4), 881-890.

Rollin, O., Bretagnolle, V., Decourtye, A., Aptel, J., Michel, N., Vaissiere, B. E., \& Henry, M. (2013). Differences Of floral resource use between honey bees and wild bees in an intensive farming system. Agriculture, Ecosystems and Environment , 179 , 78-76. https://doi.org/10.1016/j.agee.2013.07.007

Roulston, T'ai H., \& Cane, J. H. (2002). The effect of pollen protein concentration on body size in the sweat bee Lasioglossum zephyrum (Hymenoptera: Apiformes). Evolutionary Ecology , 16 (1), 49-65. https://doi.org/10.1023/A:1016048526475

Roulston, T H, Cane, J. H., \& Buchmann, S. L. (2000). What governs the protein content of pollen: pollinator preferences, pollen-pistil interactions, or phylogeny? Ecological Monographs , 70 (4), 617-643.

Ruedenauer, F. A., Raubenheimer, D., Kessner-Beierlein, D., Grund-Mueller, N., Noack, L., Spaethe, J., \& Leonhardt, S. D. (2020). Best be(e) on low fat: linking nutrient perception, regulation and fitness. Ecology Letters , 23 (3), 545-554. https://doi.org/10.1111/ele.13454

Ruedenauer, F. A., Spaethe, J., Kooi, C. J. Van Der, \& Leonhardt, S. D. (2019). Pollinator or pedigree : which factors determine the evolution of pollen nutrients ? Oecologia , (0123456789). https://doi.org/10.1007/s00442-019-04494-x

Saifuddin, M., \& Jha, S. (2014). Colony-Level Variation in Pollen Collection and Foraging Preferences Among Wild-Caught Bumble Bees (Hymenoptera: Apidae). Environmental Entomology , 43 (2), 393-401. https://doi.org/10.1603/en13261

Saleh, N., \& Chittka, L. (2007). Traplining in bumblebees (Bombus impatiens): A foraging strategy's ontogeny and the importance of spatial reference memory in short-range foraging. Oecologia ,151 (4), 719730. https://doi.org/10.1007/s00442-006-0607-9

Seeley, T. D., Camazine, S., \& Sneyd, J. (1991). Collective decision-making in honey bees: How colonles choose among nectar sources.Behavioral Ecology and Sociobiology , 28 (4), 277-290.

Somme, L., Vanderplanck, M., Michez, D., Lombaerde, I., Moerman, R., Wathelet, B., .. Jacquemart, A. L. (2015). Pollen and nectar quality drive the major and minor floral choices of bumble bees. Apidologie , 46 (1), 92-106. https://doi.org/10.1007/s13592-014-0307-0 
Visscher, P. K., \& Seeley, T. D. (1982). Foraging strategy of honeybee colonies in a temperate deciduous forest. Ecology, 63 (6), 1790-1801.

Von Frisch, K. (1967). The dance language and orientation of bees . Cambridge, MA: Belknap Press of Harvard University Press.

Wood, T. J., Kaplan, I., \& Szendrei, Z. (2018). Wild Bee Pollen Diets Reveal Patterns of Seasonal Foraging Resources for Honey Bees.Frontiers in Ecology and Evolution , 6 (December). https://doi.org/10.3389/fevo.2018.00210

Woodgate, J. L., Makinson, J. C., Lim, K. S., Reynolds, A. M., \& Chittka, L. (2017). Continuous Radar Tracking Illustrates the Development of Multi-destination Routes of Bumblebees. Scientific Reports , 7 (1), 17323. https://doi.org/10.1038/s41598-017-17553-1

\section{Figures}

Figure 1. Relative abundance of plant families in pollen collected by A) each bee species and B) during each period.
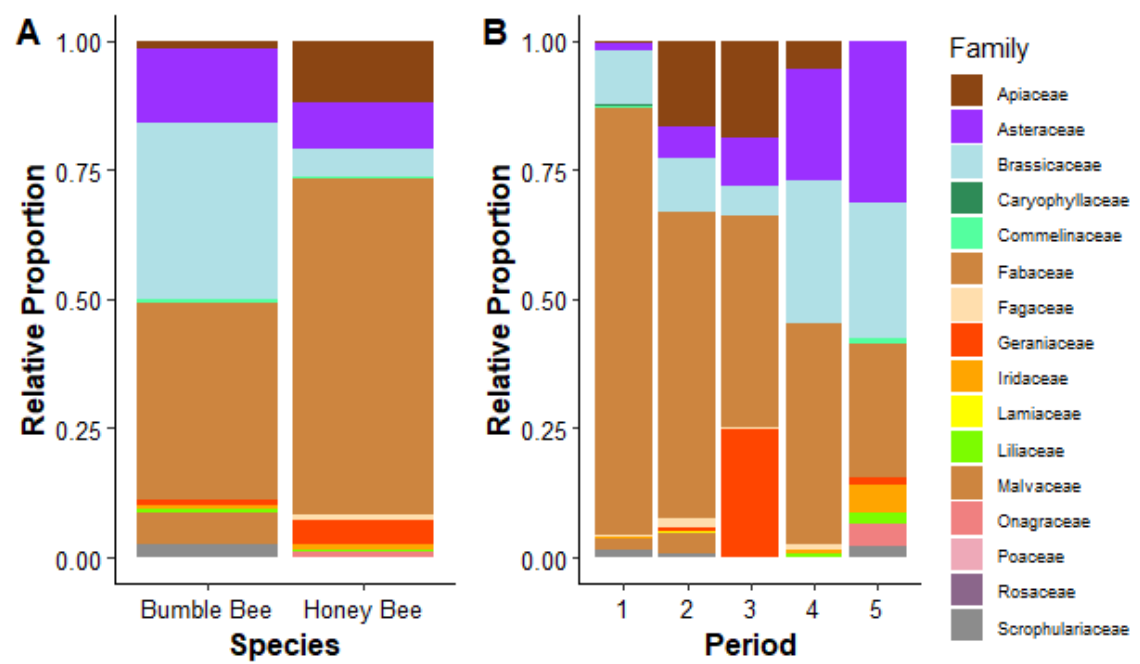

Figure 2. Interaction between bee species and period in the proportion of pollen foragers (mean \pm se) returning to the hive with one pollen morphotype (A) or pollen from one plant family (B). Statistically significant differences between bee species at each period are indicated by $* \mathrm{P}<0.05,{ }^{* *} \mathrm{P}<0.01, * * *, \mathrm{P}$ $<0.001$. 

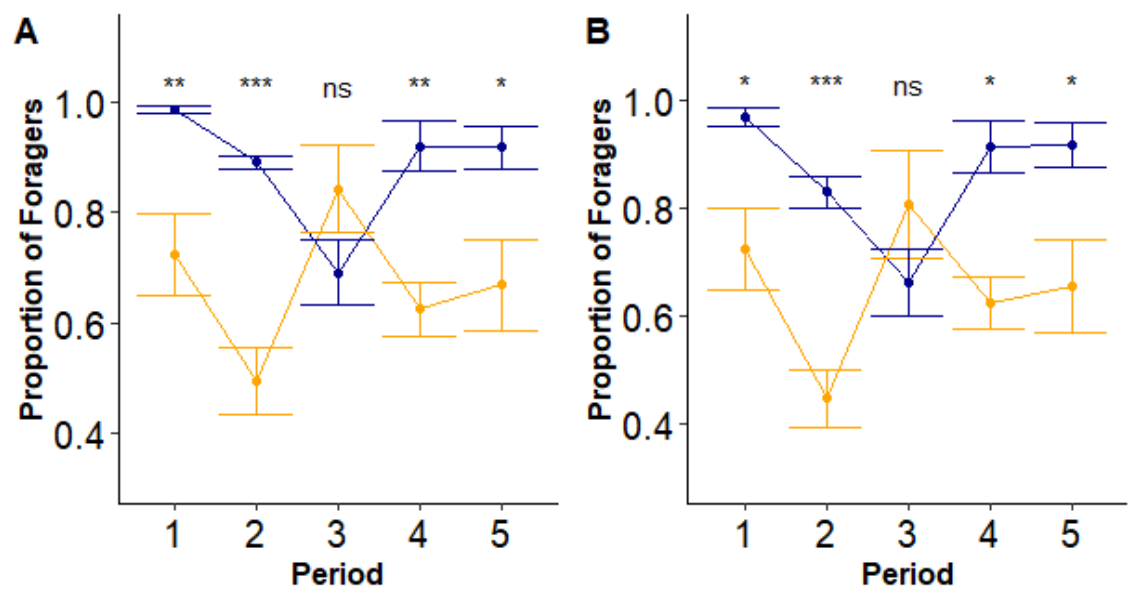

$\rightarrow$ Bumble Bee $\rightarrow$ Honey Bee

Figure 3. (A) Interaction between bee species and period on pollen richness, based on plant family (mean \pm se). Statistically significant differences among bee species during each period are indicated by $* \mathrm{P}<0.05$, ${ }^{* *} \mathrm{P}<0.01,{ }^{* * *}, \mathrm{P}<0.001$. (B) The impact of period on pollen diversity with different letters indicating statistically significant differences among periods.
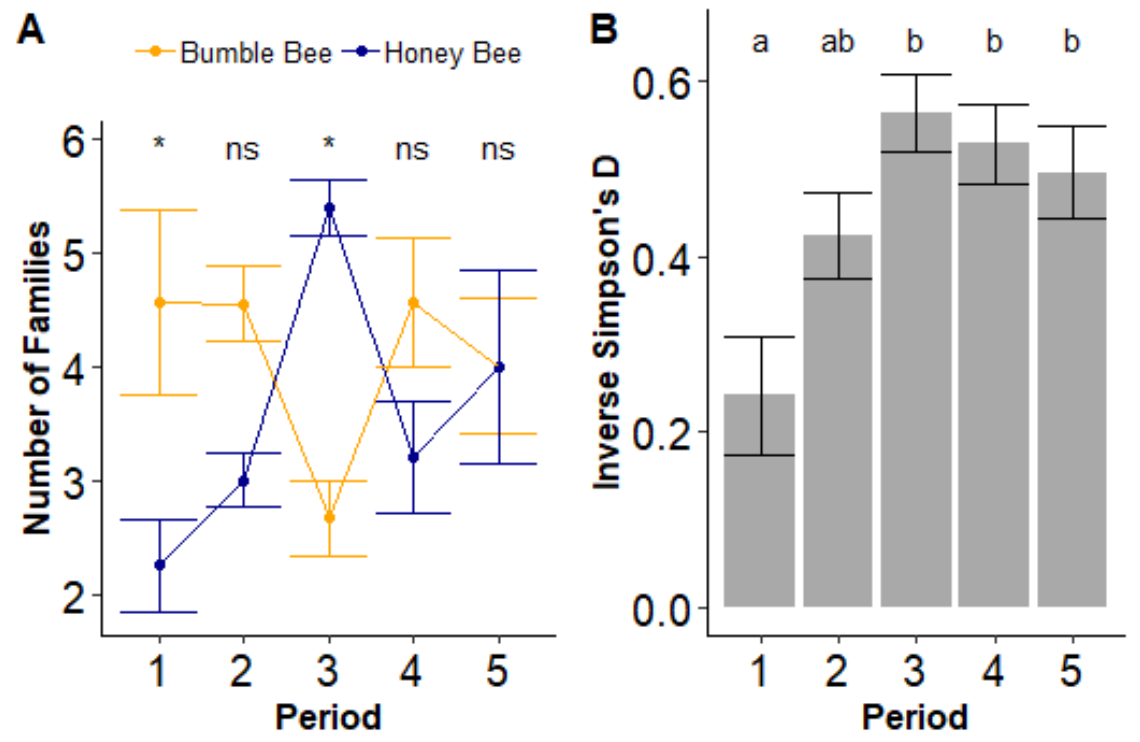

Figure 4. Pollinator preference. The proportion of each pollen morphotype found in bee collected pollen pellets and in resource surveys for (A) bumble bees and (B) honey bees. An asterisk indicated a bee species collecting more pollen from a morphotype than expected based upon its availability $(*)$. Note different scales on the y-axis. 


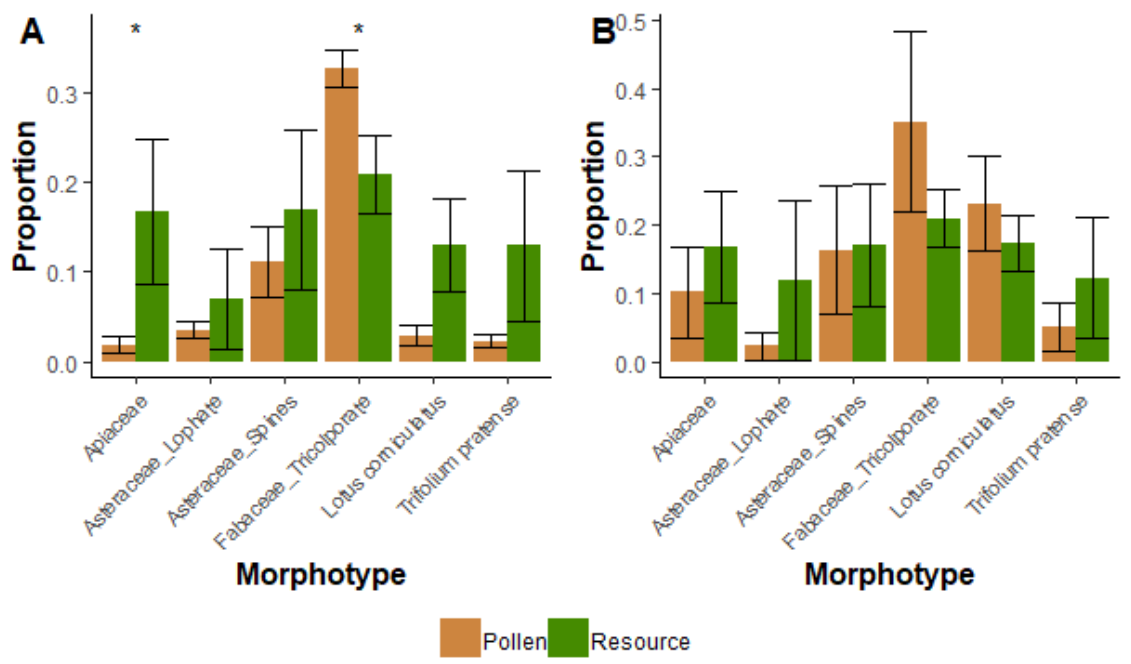

\section{Tables}

Table 1. Range of dates for collection of pollen pellets for each of the five periods over the three sites, and the associated resource availability surveys, which were conducted each month from June to September.

\begin{tabular}{lll}
\hline Period & Pollen Collection Dates & Comparable Resource Period \\
\hline 1 & June 14- 27 & June \\
2 & July 1- 13 & July \\
3 & July 23- August 2 & July \\
4 & August 8- 25 & August \\
5 & August $30-$ September 13 & September \\
\hline
\end{tabular}

Table 2: Plant families identified in pollen pellets, and plant families and species identified in resource availability surveys, along with the associated morphotype classifications.

\begin{tabular}{|c|c|c|c|}
\hline Family & $\begin{array}{l}\text { Species Identified in } \\
\text { Resource Surveys }\end{array}$ & Pollen Morphotype & Resource Morphotype \\
\hline Apiaceae & $\begin{array}{l}\text { Daucus carota Pastinaca } \\
\text { sativa }\end{array}$ & Apiaceae & Apiaceae \\
\hline Asteraceae & $\begin{array}{l}\text { Cichorium intybus } \\
\text { Taraxicum officinale } \\
\text { Hieracium canadense }\end{array}$ & Asteraceae_Lophate & Asteraceae_Lophate \\
\hline Asteraceae & $\begin{array}{l}\text { Tagetes spp. Erigeron } \\
\text { annuus Rudbeckia hirta } \\
\text { Cirsium arvense Cirsium } \\
\text { vulgare Solidago } \\
\text { canadense }\end{array}$ & Asteraceae_Spines & Asteraceae_Spines \\
\hline Brassicaceae & None & Brassicaceae & None \\
\hline Caryophyllaceae & $\begin{array}{l}\text { Stellaria media Silene } \\
\text { latifolia }\end{array}$ & Caryophyllaceae & Caryophyllaceae \\
\hline Commelinaceae & None & Commelinaceae & None \\
\hline
\end{tabular}




\begin{tabular}{llll}
\hline Family & $\begin{array}{l}\text { Species Identified in } \\
\text { Resource Surveys }\end{array}$ & Pollen Morphotype & Resource Morphotype \\
\hline Fabaceae & Medicago sativa & Fabaceae_Tricolporate & Fabaceae_Tricolporate \\
& $\begin{array}{l}\text { Securigera varia } \\
\text { Trifolium repens Lotus } \\
\text { corniculatus Trifolium } \\
\text { pratense }\end{array}$ & $\begin{array}{l}\text { Lotus corniculatus } \\
\text { Trifolium pratense }\end{array}$ & $\begin{array}{l}\text { Lotus corniculatus } \\
\text { Trifolium pratense }\end{array}$ \\
& None & & \\
Fagaceae & None & Fagaceae & None \\
Geraniaceae & None & Geraniaceae & None \\
Iridaceae & None None & Iridaceae & None \\
Liliaceae & Hemerocallis Liliaceae & None None \\
Lamiaceae & Monarda fistulosa & None Monarda fistulosa & None Monarda fistulosa \\
& None & Onagraceae & \\
Onagraceae & Leles spp. & None & None \\
Oxalidaceae & Linaria vulgaris & None & Leles spp. \\
Plantaginaceae & Oxalis spp. & None & Linaria vulgaris \\
Oxalidaceae & Phlox spp. & None & Oxalis spp. \\
Polemoniaceae & Phleum pratense & Poaceae & Phlox spp. \\
Poaceae & Potentilla spp. & Rosaceae & Poaceae \\
Rosaceae & Solanum nigrum & None & Rosaceae \\
Solanaceae & None & Tilia americana & Solanum nigrum \\
Malvaceae & None & None \\
Scrophulariaceae & & None \\
\hline
\end{tabular}

Table 3: The effects of site, period, species, and their two-way interactions on flower constancy, pollen richness, and pollen diversity for linear mixed models based on (A) pollen morphotype or (B) plant family. Statistically significant factors are indicated in bold (P [?] 0.05).

\begin{tabular}{llllll}
\hline Pollen Morphotype & Pollen Morphotype & Pollen Morphotype & Pollen Morphotype & Pollen Morphotype & Pollen Morpho \\
\hline Variable & Constancy & Constancy & Constancy & Richness & Richness \\
Factor & DF & F & P & DF & F \\
Site & 2,7 & 0.56 & 0.593 & 2,7 & 0.26 \\
Period & 4,7 & 5.06 & $\mathbf{0 . 0 3 1}$ & 4,7 & 0.81 \\
Species & 1,7 & 20.41 & $\mathbf{0 . 0 0 3}$ & 1,7 & 0.78 \\
Period x Species & 4,7 & 5.37 & $\mathbf{0 . 0 2 7}$ & 4,7 & 3.71 \\
Site x Species & 2,7 & 1.83 & 0.230 & 2,7 & 0.81 \\
Site x Period & 8,7 & 1.39 & 0.338 & 8,7 & 1.13 \\
Pollen Family & Pollen Family & Pollen Family & Pollen Family & Pollen Family & Pollen Family \\
Variable & Constancy & Constancy & Constancy & Richness & Richness \\
Factor & DF & F & P & DF & F \\
Site & 2,7 & 0.29 & 0.756 & 2,7 & 0.13 \\
Period & 4,7 & 2.95 & 0.101 & 4,7 & 0.44 \\
Species & 1,7 & 24.19 & $\mathbf{0 . 0 0 1}$ & 1,7 & 1.35 \\
Period x Species & 4,7 & 5.34 & $\mathbf{0 . 0 2 7}$ & 4,7 & 4.11 \\
Site x Species & 2,7 & 1.85 & 0.227 & 2,7 & 0.66 \\
Site x Period & 8,7 & 1.15 & 0.433 & 8,7 & 0.81 \\
\hline
\end{tabular}

Table 4: The effects of site and survey period on plant richness and diversity estimated at the species, family, 
or morphotype levels using linear mixed models. Significant factors are in bold (P [?] 0.05).

\begin{tabular}{lllllll}
\hline Level & Species & Species & Species & Family & Family & Family \\
\hline & DF & F & P & DF & F & P \\
Plant Richness & Plant Richness & Plant Richness & Plant Richness & Plant Richness & Plant Richness & Plant Richness \\
Site & 2,5 & 1.52 & 0.304 & 2,5 & 5.95 & $\mathbf{0 . 0 4 7}$ \\
Survey Period & 3,5 & 0.78 & 0.556 & 3,5 & 1.18 & 0.404 \\
Plant Diversity & Plant Diversity & Plant Diversity & Plant Diversity & Plant Diversity & Plant Diversity & Plant Diversity \\
Site & 2,5 & 0.46 & 0.654 & 2,5 & 2.82 & 0.151 \\
Survey Period & 3,5 & 0.91 & 0.50 & 3,5 & 3.28 & 0.117 \\
\hline
\end{tabular}

Table 5. Preferences of honey bees and bumble bees overall (MANOVA), and for individual pollen morphotypes (ANOVAs).

\begin{tabular}{lllllll}
\hline & Honey bee & Honey bee & Honey bee & Bumble bee & Bumble bee & Bumble bee \\
\hline Morphotype & $\mathrm{DF}$ & $\mathrm{F}$ & $\mathrm{P}$ & $\mathrm{DF}$ & $\mathrm{F}$ & $\mathrm{P}$ \\
Overall MANOVA & 6,1 & 1.68 & 0.530 & 6,1 & 153.8 & 0.062 \\
Apiaceae & 1,6 & 1.18 & 0.319 & 1,6 & 6.53 & $\mathbf{0 . 0 4 5}$ \\
Asteraceae_Lophate & 1,6 & 1.07 & 0.341 & 1,6 & 0.36 & 0.569 \\
Asteraceae_Spines & 1,6 & 0.00 & 0.961 & 1,6 & 0.36 & 0.572 \\
Fabaceae_Tricolporate & 1,6 & 1.03 & 0.349 & 1,6 & 6.14 & $\mathbf{0 . 0 4 8}$ \\
Lotus corniculatus & 1,6 & 0.22 & 0.656 & 1,6 & 3.62 & 0.106 \\
Trifolium pretense & 1,6 & 0.82 & 0.401 & 1,6 & 1.65 & 0.247 \\
\hline
\end{tabular}

\section{Appendix}

Table S1 : The number of days where pollen was collected, and the total number of pollen pellets available per period and site for each bee species.

\begin{tabular}{llllll}
\hline & & Bumble Bee & Bumble Bee & Honey Bee & Honey Bee \\
\hline Period & Site & Number of Days & Total Pollen Pellets & Number of Days & Total Pollen Pellets \\
1 & 1 & 2 & 36 & 2 & 76 \\
& 2 & 2 & 41 & 3 & 119 \\
& 3 & 3 & 34 & 3 & 118 \\
2 & 1 & 3 & 58 & 3 & 119 \\
& 2 & 3 & 59 & 3 & 88 \\
3 & 3 & 3 & 55 & 3 & 115 \\
& 1 & 1 & 9 & 0 & 0 \\
4 & 2 & 1 & 3 & 3 & 100 \\
4 & 3 & 1 & 4 & 2 & 76 \\
& 1 & 3 & 27 & 2 & 66 \\
5 & 2 & 2 & 26 & 2 & 38 \\
& 3 & 2 & 37 & 1 & 47 \\
& 1 & 2 & 36 & 2 & 29 \\
Total: & 2 & 3 & 22 & 2 & 39 \\
\hline
\end{tabular}


Fig. S1: Rarefaction curve illustrating the number of pollen grains needed to identify all pollen morphotypes present in a pollen pellet.

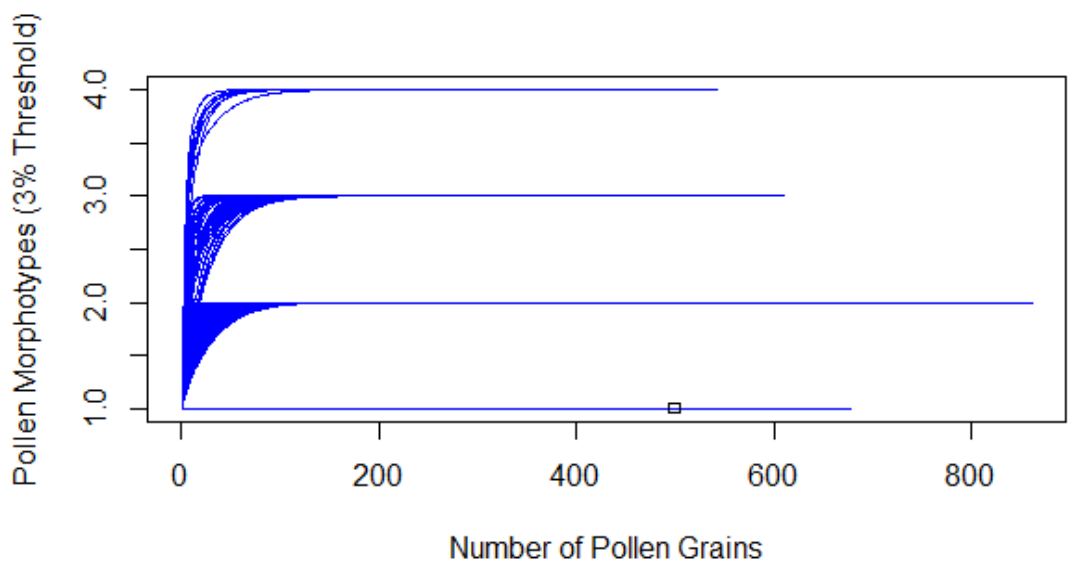

Fig. S2: The abundance of the different plant families available (resources) at each site (A) and survey period (B).
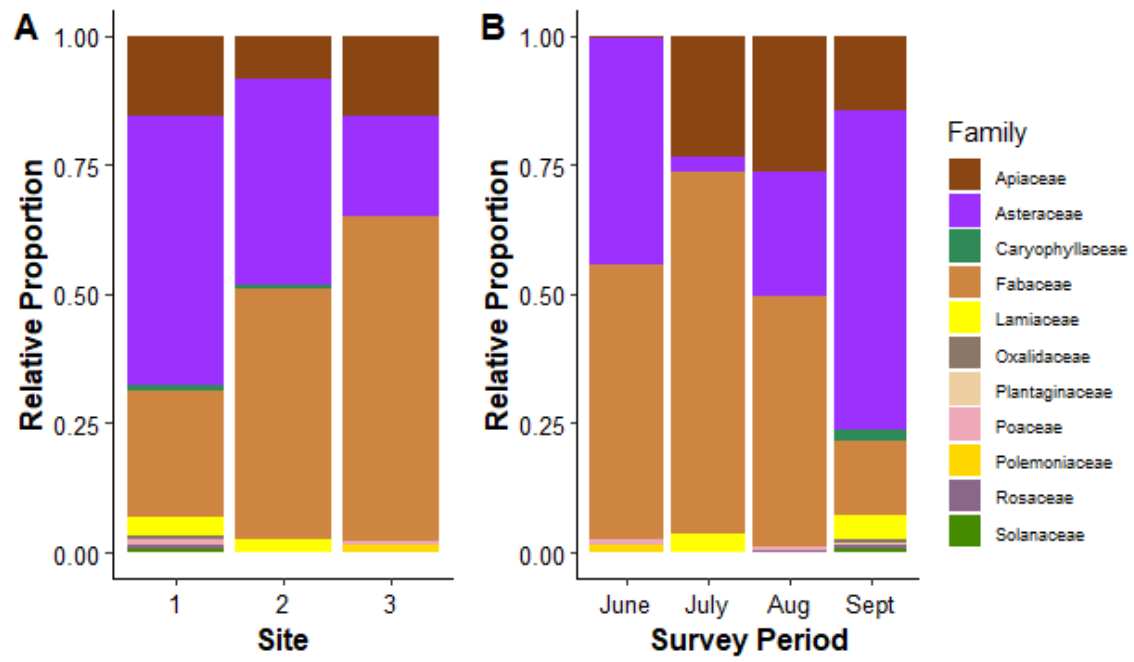

Fig. S3: The plant families identified in the pollen pellets collected by bumble bees or honey bees at a given period (A) or site (B). 


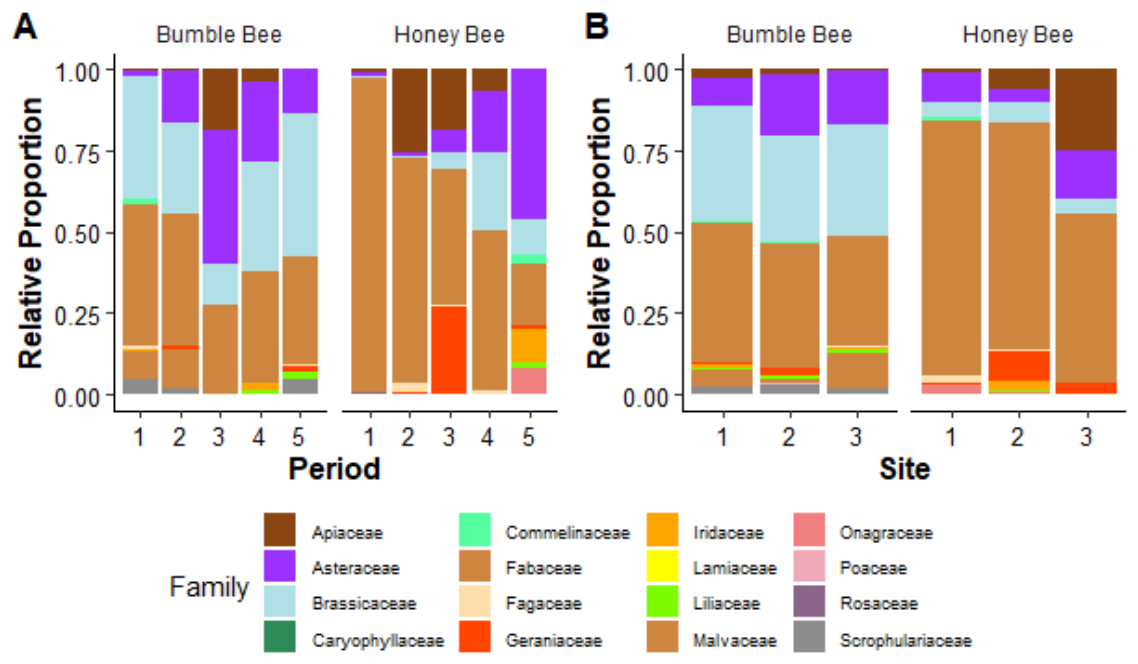

